Open Access

Original Article

\title{
Assessment of episodes of pneumonia and diarrhea in vaccinated and unvaccinated children under 60 months of age
}

\author{
Shireen Qassim Bham 1 , Farhan Saeed ${ }^{2}$, \\ Muhammad Athar Khan ${ }^{3}$, Rashid Naseem Khan ${ }^{4}$
}

\section{ABSTRACT}

Objective: To assess the episodes of pneumonia and diarrhea in vaccinated and unvaccinated children under 60 months of age.

Methods: This descriptive cross-sectional study was carried out at Darul Sehat Hospital and SESSI, Karachi in the Department of Pediatrics from $1^{\text {st }}$ November 2018 to $3^{\text {rd }}$ February 2019. An interview based questionnaire was administered and selection of participants was done by convenience sampling. Total of 196 participants were selected for interview.

Results: Total 196 participants were interviewed which included mothers of children between the age group of 1- 60 months. The questions were entered on the questionnaire after taking consent from the mothers. Among them, males were $98(52.7 \%)$ and females were $88(47.3 \%)$. One hundred seventy two $(88.7 \%)$ children were vaccinated for pneumococcal and rotavirus whereas unvaccinated children were $22(11.3 \%)$. There was an incidence of $66(63.5 \%)$ for loose watery diarrhea. In vaccinated children, grading of diarrhea was found to be severe cases as 30 (34.9\%), moderate cases as $27(31.4 \%)$ and mild cases as 29(33.7\%). For unvaccinated children, severe cases were $12(66.7 \%)$ and for mild and moderate cases were $(11.1 \%)$ and $04(22.2 \%)$ respectively with $p$ value of 0.035 . As compared to their unvaccinated counterparts, the frequency of severe pneumonia was far less than cough and cold in vaccinated children $(p<0.001)$

Conclusion: There is significant reduction in cases of severe pneumonia in children receiving pneumococcal vaccine as compared to children receiving Rota vaccine there is moderate reduction in cases of severe diarrhea. The overall coverage of Pneumococcal and Rota vaccines was higher in our sample population. Efforts should be made to increase the awareness of Rotavirus vaccination in order to have better coverage in future.

KEYWORDS: Diarrhea, Pneumonia, Rota virus, Pneumococcal vaccine.

doi: https://doi.org/10.12669/pjms.36.7.2996

How to cite this:

Bham SQ, Saeed F, Khan MA, Khan RN. Assessment of episodes of pneumonia and diarrhea in vaccinated and unvaccinated children under 60 months of age. Pak J Med Sci. 2020;36(7):1596-1600. doi: https://doi.org/10.12669/pjms.36.7.2996

This is an Open Access article distributed under the terms of the Creative Commons Attribution License (http://creativecommons.org/licenses/by/3.0), which permits unrestricted use, distribution, and reproduction in any medium, provided the original work is properly cited.

\footnotetext{
Correspondence:

Dr. Shireen Qassim Bham, MBBS, FCPS. Associate Professor, Department of Pediatrics, Liaquat College of Medicine \& Dentistry, Karachi, Pakistan.

Email: drshbham@yahoo.com

* Received for Publication:

* Revision Received:

* Revision Accepted:

June 2, 2020

September 9, 2020

September 15, 2020
}

\section{INTRODUCTION}

In children less than 60 months of age, pneumonia and diarrhea are one of major reasons of morbidity and mortality and main reason for high economic cost. ${ }^{1}$ Pneumonia is the major cause of childhood mortality globally with 0.7 to 1 million death of children under the age of 60 month annually. ${ }^{2}$ Pneumonia lead to 935,000 deaths in children globally in $2013 .{ }^{3}$ Streptococcus pneumonia is the pathogen mostly

$\begin{array}{lllll}\text { Pak J Med Sci } \quad \text { November - December } 2020 & \text { Vol. } 36 & \text { No. } 7 & \text { www.pjms.org.pk } 1596\end{array}$ 
affecting infants, causing an estimated killing of 1.2 million worldwide. ${ }^{2}$ In developing countries pneumonia accounts for $15 \%$ of total overall mortality in children under five years of age worldwide. ${ }^{4}$ It has been estimated that $29 \%$ of all diarrheal deaths in children $<5$ years of age is due to rotavirus and about $23 \%$ of rotavirus deaths are in the Indian subcontinent.. Studies have estimated that specific PCV formulations could reduce overall under-five mortality by $11 \%{ }^{2}$

In young children, Rotavirus is a leading cause of diarrhea. Rotavirus infection was responsible for more than 258 million episodes of diarrhea among children younger than 60 months. ${ }^{5}$ Rotavirus accounts for $29 \%$ of overall deaths due to diarrhea in children under-60 months of age with $23 \%$ of deaths due to rota virus occurring in developing countries like Indo Pak subcontinent. ${ }^{6}$ Annually Rotavirus is responsible for $>500,000$ deaths worldwide among infants and very young children, with $90 \%$ of these deaths occurring in African and Asian countries alone. Rotavirus infection alone accounts for $40 \%$ of all pediatric hospitalizations for diarrhea. Hence other than clean water usage, personal hygiene and good medical care, rotavirus vaccine is considered to be a safest strategy to decrease the burden of severe and fatal rotavirus diarrhea. ${ }^{7}$

There are limited studies on diarrhea and pneumonia after the introduction of pneumococcal and Rota virus vaccine so further work is needed in this context. Also limited number of studies from a developing countries to report the frequency of both diarrhea and pneumonia in vaccinated and unvaccinated children in a well-defined catchment area. In this study we assessed vaccinated and unvaccinated children for the frequency of pneumonia and diarrhea in children under the age of 60 months at tertiary care hospital, Karachi.

\section{METHODS}

This descriptivecross-sectional study was, carried out at Darul Sehat Hospital and SESSI after the ethical approval (Ref. No. DSH/IRB/2020/0014, dated May 5, 2020), Karachi in the Department of Pediatrics from $1^{\text {st }}$ November 2018 to $3^{\text {rd }}$ February. The minimum sample size came out 196 by using Raosoft sample size calculator. An interview based questionnaire was administered and selection of participants was done by convenience sampling. All children age one month to 60 months coming to outpatient clinic with their mothers for any illness were included in this study. A written informed consent was taken from parents. The participants were asked for age, gender, number of vaccines received, type of vaccines, duration of illness, history of previous episodes, breastfeeding, reason for vaccination, reason for no vaccination which were taken as variables.

Diarrhea is defined as stools $>3$ episode in 24 hours. Mild Diarrhea when child had no visit to health care subsided itself or with home remedies, moderate when child visited primary health care /clinic for treatment and rehydration performed orally at home and severe when child visited emergency department for treatment at hospital. ${ }^{8,9}$

WHO IMNCI guidelines were used for diagnosis on pneumonia are as follows: Cough and cold when child has runny nose and cough but no fast breathing. Pneumonia when child had fast breathing and taken to hospital and Severe pneumonia when child has chest in drawing or any danger signs (reluctant to feed/unconscious, vomiting every feed, having convulsions). ${ }^{10}$

Data was entered and analyzed using SPSS version 21 . The frequency (\%) and mean+SD were reported for qualitative and quantitative variables. Chi Square test was used to compare severity of diarrhea and pneumonia in vaccinated and unvaccinated children at $\mathrm{p}$ value $<0.05$ significant.

\section{RESULTS}

One hundred ninety-six participants were interviewed which included mothers of children between the age group of 1- 60 months. The questions were entered on the questionnaire after taking consent from the mothers. Among them, males were $98(52.7 \%)$ and females were $88(47.3 \%)$. One hundred seventy-two $(88.7 \%)$ children were vaccinated for pneumococcal and rotavirus whereas unvaccinated children were 22(11.3\%). There was a frequency incidence of $66(63.5 \%)$ for loose watery diarrhea.

The Fig.1 shows the frequency of diarrhea according to its severity in vaccinated; mild $29(33.7 \%)$, moderate $27(31.4 \%)$, severe $30(34.9 \%)$, and unvaccinated participants; mild 02 (11.1\%), moderate $04(22.2 \%)$, severe $12(66.7 \%)$ accordingly.

As compared to their unvaccinated counterparts, the frequency of severe pneumonia $(16.9 \%)$ was far less than cough and cold $(63.1 \%)$ in vaccinated children $(\mathrm{p}<0.001)$. Fig-II

\section{DISCUSSION}

In Children age less than 60 months of age worldwide; gastrointestinal and respiratory 
Table-I: Demographic and clinical characteristics of study participants $(n=196)$.

\begin{tabular}{|c|c|c|}
\hline Variables & & $n(\%)$ \\
\hline \multirow[t]{2}{*}{ Gender } & Male & $98(52.7)$ \\
\hline & Female & 88(47.3) \\
\hline \multirow{2}{*}{$\begin{array}{l}\text { Vaccine received Rota, } \\
\text { pneumococcal }\end{array}$} & Both & $172(88.7)$ \\
\hline & None & $22(11.3)$ \\
\hline Age in months & $\begin{array}{l}\text { Mean } \pm \text { SD, } \\
\text { Median (min, max) }\end{array}$ & $\begin{array}{c}25.6 \pm 18.3 \\
24(1-60)\end{array}$ \\
\hline \multirow{3}{*}{$\begin{array}{l}\text { Grading of } \\
\text { pneumonia }\end{array}$} & Severe pneumonia & $38(25.3)$ \\
\hline & Pneumonia & 29(19.3) \\
\hline & Cold and cough & $83(55.4)$ \\
\hline \multirow{2}{*}{$\begin{array}{l}\text { History of previous } \\
\text { episodes of pneumonia }\end{array}$} & Yes & $130(68)$ \\
\hline & No & $61(32)$ \\
\hline \multirow[t]{3}{*}{ Grading of diarrhea } & Mild & $31(29.8)$ \\
\hline & Moderate & $31(29.8)$ \\
\hline & Severe & $42(40.4)$ \\
\hline \multirow{2}{*}{$\begin{array}{l}\text { History of } \\
\text { previous episodes }\end{array}$} & Yes & $88(48)$ \\
\hline & No & $95(52)$ \\
\hline \multirow[t]{2}{*}{ Reason of vaccination } & Health concern & $50(36.7)$ \\
\hline & Knowledge & $86(63.3)$ \\
\hline \multirow[t]{4}{*}{ Reason of no vaccination } & Fear of side effects & $19(32.3)$ \\
\hline & No knowledge & $16(27.1)$ \\
\hline & Cost & $6(10.1)$ \\
\hline & Other & $18(30.5)$ \\
\hline \multirow[t]{4}{*}{ Type of diarrhea } & $\begin{array}{l}\text { Acute Watery } \\
\text { diarrhea }\end{array}$ & $66(63.5)$ \\
\hline & $\begin{array}{l}\text { Diarrhea with } \\
\text { mucous }\end{array}$ & $20(19.2)$ \\
\hline & Blood in stool & $2(1.9)$ \\
\hline & Other & $16(15.4)$ \\
\hline \multirow[t]{2}{*}{ Breastfeeding } & Yes & $169(88.4)$ \\
\hline & No & $22(11.6)$ \\
\hline
\end{tabular}

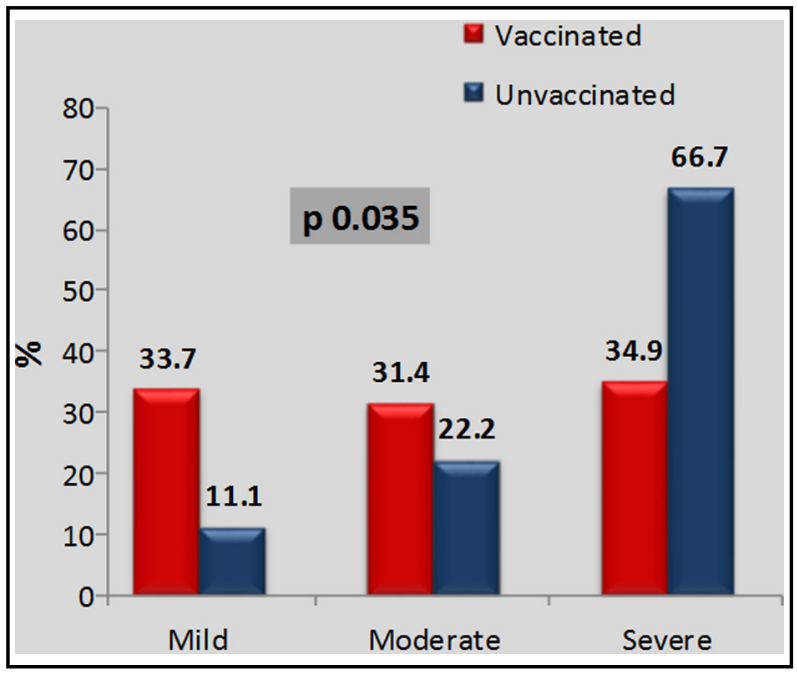

Fig.1: Severity of Diarrhea in Vaccinated and Unvaccinated Children According to IMNCI.
Table-II: Duration of Illness of Pneumonia and Diarrhea.

\begin{tabular}{ll}
\hline Variables & \multicolumn{1}{c}{$\begin{array}{c}\text { Mean } \pm \text { SD, } \\
\text { Median(Min-Max) }\end{array}$} \\
\hline Duration of Illness of Pneumonia & $7.1 \pm 6.4,5(1-30)$ \\
If Yes, At What Age? (Pneumonia) & $9.7 \pm 13.2,4(1-60)$ \\
Duration of Illness of diarrhea & $6 \pm 8.1,4(0-48)$ \\
If Yes, At What Age? (Diarrhea) & $10.2 \pm 12.6,6(1-60)$ \\
\hline
\end{tabular}

infections are the two leading causes accounting for over two million deaths annually. In our study overall vaccination coverage was $88.7 \%$ for both Rota and Pneumococcal vaccines. In India, Rota vaccine coverage was $65 \%$ in 2016 and $61 \%$ in $2017^{11}$ where as in Canadian study the coverage was 75 to $90 \%$ in different cities. ${ }^{12}$ In another Indian study, pneumococcal coverage was $64 \%$ for PCV10 and $74.6 \%$ for PCV $13 .{ }^{13}$ In other studies, Brazil shows overall vaccination coverage of $53.4 \%^{14}$ and in Uganda it was $42 \%{ }^{15}$ both had far less coverage than in our study. Overall Global vaccination coverage according to $\mathrm{WHO}$ remains at $85 \%$, global coverage for pneumococcal was estimated at $44 \%$ and for Rota it was estimated at $28 \% .{ }^{16}$ Comparison to these studies shows that the coverage in our part of world is comparatively better to neighboring countries.

Our study shows mean age of 10 months with median age of 06 month (1-60) which is similar to paper reviewed by WHO which shows median age in less developed countries as $06-09$ months. ${ }^{7}$ Whereas in India the peak age is between 9 to 11 month $^{16}$ and 6 to 15 months in another Indian study. ${ }^{17}$ There were $52.7 \%$ were male and $47.3 \%$ were female with 1:1 male to female ratio in our

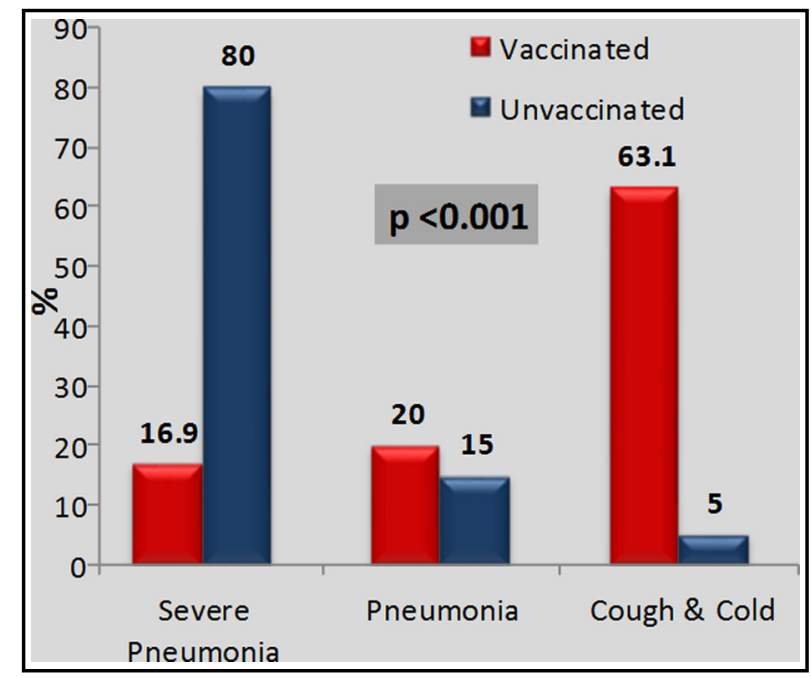

Fig.2: Severity of Pneumonia in Vaccinated and Unvaccinated Children According to IMNCI. 
study while study done in India shows M:F ratio of $0.97: 1^{18}$ with female predominance.

The frequency of watery diarrhea in our study was $63.4 \%$. the incidence of diarrheal disease in study done in Nigeria children under five years was $51.8 \% .{ }^{19}$ A peak incidence of $1.05(95 \%$ confidence interval [CI]: 0.64, 1.64) infections per child-year was observed in the first six months of life in Vellore, while in Karonga incidence was greatest in the second six months of life (1.41 infections per child year [95\% CI: 0.79, 2.29]). ${ }^{20}$ In unvaccinated children, severe diarrhea was the most prevailing one with $66.7 \%$ with $p$ value being 0.035 . In vaccinated children, mild diarrhea was seen in $33.7 \%$ moderate diarrhea in $31.4 \%$ and severe diarrhea in $34.9 \%$ children in comparison to study done in India which had $73.7 \%$ as moderately severe disease and $26.3 \%$ as severe disease. There was no case of mild disease. ${ }^{17} \mathrm{In}$ other study with children under-five, it showed $64.8 \%$ of diarrheal episodes are mild, $34.7 \%$ are moderate, and $0.5 \%$ are severe..$^{21}$ This clearly shows Rota virus vaccination significantly decreases the burden of disease in community and is effective in preventing severe rotavirus gastroenteritis.

Breast feeding has an important role in prevention of Rota virus gastroenterits thus reducing the risk of subsequent Rota virus infection. Our study shows, $88.4 \%$ children were given breast feeding while in Indian study it was $46.4 \%{ }^{18}$ In study by Sushmita Das, the prevalence of breastfed infants to non breast feed infants with diarrhea was $23.4 \%$ as compared to $76.5 \% .^{22}$ This shows breast feeding has a protective effect against diarrhea. Effective measure like use of clean water and effective personal hygiene along with breast feeding and proper doses of Rota virus vaccination leads to corresponding decline in Rota virus gastroenteritis.

In our study mean age for children with pneumonia is 7.1 months as compared to study done in Dhaka which shows 11 months $^{23}$ and median age 2.4 months as compared to a multicenter study by Thomas Bennet, Valentine Sanchez et al which shows median age is 14 months. ${ }^{24}$ In our study frequency of severe pneumonia is $25.3 \%$, pneumonia $29 \%$ and cold and cough $55.4 \%$ as compared to study in Kenya which shows $74 \%$ were cough and cold and $22 \%$ were severe pneumonia. ${ }^{25}$ In vaccinated children severe pneumonia decrease to $16.9 \%$ and cough and cold increased to $63.1 \%$ in our study which is proved by study in Gambia that states vaccine effectiveness increase with larger number of doses. ${ }^{26}$
The reports clearly show that after the introduction of PCV10/13 vaccine there is significant evidence of reduction in hospitalization for pneumonia with an estimated decline in the incidence of radiological pneumonia to $24 \%$ and $47 \%$ in studies done in Gambia ${ }^{26}$ and Israel $^{27}$ respectively. The addition of Pneumococcal vaccine to EPI is an essential milestone in the fight against pneumonia. The use of this vaccine will not only reduce significant number of new cases of pneumonia but has great potential to save thousands of lives.

Strengths of the study: The strength of our study is despite unavailability of data to study combine effect of Rota virus and pneumococcal vaccine, we tried to evaluate the effect of these vaccines in children less than 60 months of age in Pakistan. It has proven to be cost effective by reducing the disease burden.

Limitations of the study: Because of short duration we could not asses the long-term effect.

\section{CONCLUSION}

There is significant reduction in cases of severe pneumonia in children receiving pneumococcal vaccine as compared to children receiving Rota vaccine while there is moderate reduction in cases of severe diarrhea. The overall coverage of Pneumococcal and Rota vaccines was higher in our sample population. Efforts should be made to increase the awareness of Rotavirus vaccination in order to have better coverage in future.

Acknowledgement: We are thankful to final year MBBS students of Liaquat College of Medicine \& Dentistry, Fatima Siraj Ahmed, Syeda Sara Afsar and Tayyeb Mehmood for their support in collection and entry of data. We are thankful to first year MBBS student of Dow University of Health Sciences Umer Hayat Ahmed Sharif for helping in manuscript preparation.

\section{Declaration of interest: None.}

Financial Disclosures: None.

\section{REFERENCES}

1. Lugangira K, Kazaura M, Kalokola F. Morbidity and mortality of children aged 2-59 months admitted in the Tanzania Lake Zone's public hospitals: A cross-sectional study. BMC Res Notes. 2017;10(1):502. doi: 10.1186/s13104-017-2818-z

2. Jamali T, Shahid A, Mistry R. Initiation of pneumococcal vaccine against pneumonia in Pakistan. J Ayub Med Coll Abbottabad. 2013;25(3-4):1-2 
3. Liu L, Oza S, Hogan D. Global, regional, and national causes of child mortality in 2000-13, with projections to inform post-2015 priorities: an updated systematic analysis. Lancet. 2015;385:430-440.

4. Benet T, Picot VS, Awashthi S, Pandhey N, Bavdekar A, Kawade A, et al. Severity of Pneumonia in under 5-year-old children from developing countries: A multi, prospective, observational study. Am J Trop Med Hyg. 2017;97(1):68-76. doi: 10.4269/ajtmh.16-0733

5. Troeger C, Khalil IA, Rao PC, Cao S, Blacker BF, Ahmed $\mathrm{T}$, et al. Rotavirus Vaccination and the Global Burden of Rotavirus Diarrhea Among Children Younger Than 5 Years. JAMA Pediatr. 2018;172(10):958-965. doi: 10.1001/ jamapediatrics.2018.1960

6. Prevalence of Rota Virus Infection in children below 2 years presenting with diarrhea. Med J Armed Forces India. 2014;70(2):116-119. doi: 10.1016/j.mjafi.2014.02.008

7. BenninghoffB.PerieraP,VetterV.Roleofhealthcarepractitioners in rotavirus disease awareness and vaccination - insights from a survey among caregivers. Hum Vaccin Immunother. 2020;16(1):138-147. doi: 10.1080/21645515.2019.1632685

8. Brandt KG, Castro Antunes MM, Silva GA. Acute diarrhea: evidence-based management. J Pediatr (Rio J). 2015;91(6 Suppl 1):S36-S43. doi: 10.1016/j.jped.2015.06.002

9. Guarino A, Ashkenazi S, Gendrel D, Lo Vecchio A, Shamir R, Szajewska H. European Society for Pediatric Gastroenterology, Hepatology, and Nutrition/European Society for Pediatric Infectious Diseases evidence-based guidelines for the management of acute gastroenteritis in children in Europe: Update 2014. J Pediatr Gastroenterol Nutr. 2014;59:132-152.

10. WHO. IMCI Chart Booklet. 2014 [cited 2019 Feb 21]. Available from: https://www.who.int/maternal_child_adolescent/ documents/IMCI_chartbooklet/en/

11. WHO. India: WHO and UNICEF estimates of immunization coverage. 2017. [cited 2019 Jan 01]. Available from: https:// www.who.int/immunization/monitoring_surveillance/ data/ind.pdf

12. Wilson SE, Chung H, Schwartz KL, Guttmann A, Deeks SL, Kwong JC, et al. Rotavirus vaccine coverage and factors associated with uptake using linked data: Ontario, Canada PLoS One. 2018;13(2):e0192809. doi: 10.1371/journal pone.0192809

13. Manoharan A, Jayaraman R. Pneumococcal vaccines. Indian J Med Microbiol. 2018;36:465-474. Available from: http:/ / www. ijmm.org/text.asp?2018/36/4/465/254402

14. Saraiva FO, Minamisava $\mathrm{R}$, Vieira MA, Bierrenbach $\mathrm{AL}$, Andrade AL. Vaccination Coverage and Compliance with Three Recommended Schedules of 10-Valent Pneumococcal Conjugate Vaccine during the First Year of Its Introduction in Brazil: A Cross-Sectional Study. PLoS One. 2015;10(6):e0128656. doi: 10.1371/journal.pone.0128656

15. Lindstrand A, Kalyango J, Alfven T, Darenberg J, Kadobera D, Bwanga F, et al. Pneumococcal Carriage in Children under Five Years in Uganda-Will Present Pneumococcal Conjugate Vaccines Be Appropriate? PLoS One. 2016;11(11):e0166018. doi: 10.1371/journal.pone.0166018

16. WHO. Immunization coverage by WHO. 2018 [cited 2018 Dec 23]. Available from: https://www.who.int/news-room/factsheets/detail/immunization-coverage

17. Bahl R, Ray P, Subodh S, Shambharkar P, Saxena M, Parashar $\mathrm{U}$, et al. Incidence of Severe Rotavirus Diarrhea in New Delhi, India, and G and P Types of the Infecting Rotavirus Strains. J Infect Dis. 2005;192(Suppl 1):S114-S119.

18. John BM, Devgan A, Mitra B. Prevalence of rotavirus infection in children below two years presenting with diarrhea. Med J Armed Forces India. 2014;70(2):116-119. doi: 10.1016/j.mjafi.2014.02.008

19. Ucheh IB, Eleojo AA, Tyoalumun K, Nanpen DM. Assessment of the incidence of diarrhea in children under 5 years at the Institute of Child Health, Banzazzau, Zaria. Ann Nigerian Med. 2017;11:6-10.
20. Bennett A, Nagelkerke N, Heinsbroek E, Premkumar PS, Wnek M, Kang G, et al. Estimating the incidence of rotavirus infection in children from India and Malawi from serial antirotavirus IgA titres. PLoS One. 2017;12(12):e0190256. doi: 10.1371/journal.pone.0190256

21. Lamberti LM, Fischer Walker CL, Black RE. Systematic review of diarrhea duration and severity in children and adults in low- and middle-income countries. BMC Public Health. 2012;12:276. doi: 10.1186/1471-2458-12-276

22. Das S, Sahoo GC, Das P, Singh UK, Jaiswal AK, Singh P, et al. Evaluating the Impact of Breastfeeding on Rotavirus Antigenemia and Disease Severity in Indian Children. PLoS One. 2016;11(2):e0146243. doi: 10.1371/journal.pone.0146243

23. Leung DT, Das SK, Malek MA, Qadri F, Faruque AS, Chisti MJ. Concurrent Pneumonia in Children Under 5 Years of Age Presenting to a Diarrheal Hospital in Dhaka, Bangladesh. Am J Trop Med Hyg. 2015;93(4):831-835. doi: 10.4269/ajtmh.15-0074

24. Benet T, Picot VS, Awasthi S, Pandey N, Bavdekar A, Kawade A, et al. Severity of Pneumonia in Under 5-Year-Old Children from Developing Countries: A Multicenter, Prospective, Observational Study. Am J Trop Med Hyg. 2015;93(4):831-835. doi: 10.4269 /ajtmh.15-0074

25. Agweyu A, Lilford RJ, English M, Irimu G, Ayieko $\mathrm{P}$, Akech S, et al. Appropriateness of clinical severity classification of new WHO childhood pneumonia guidance: A multi-hospital, retrospective, cohort study. Lancet Global Health. 2018;6(1):e74-e83. doi: 10.1016/S2214-109X(17)30448-5

26. Mackenzie GA, Hill PC, Sahito SM, Jeffries DJ, Hossain I, Bottomley C, et al. Impact of the introduction of pneumococcal conjugate vaccination on pneumonia in The Gambia: population-based surveillance and case-control studies. Lancet Infect Dis. 2017;17(9):965-973. doi: 10.1016/S14733099(17)30321-3

27. Greenberg D, Givon-Lavi N, Ben-Shimol S, Ziv JB, Dagan R. Impact of PCV7/PCV13 introduction on communityacquired alveolar pneumonia in children $<5$ years. Vaccine. 2015;33:4623-4629.

\section{Authors' Contribution:}

SQB, FS: Study design, data collection, Manuscript preparation, Review and final approval of manuscript and is responsible for integrity of research.

MAK: Statistical analysis\& interpretation, Drafting, Manuscript preparation.

RNK: Data collection, Manuscript preparation, Review and final approval of manuscript.

Authors:

1. Dr. Shireen Qassim Bham, FCPS. Department of Pediatrics,

2. Dr. Farhan Saeed, FCPS. Department of Pediatrics,

3. Dr. Muhammad Athar Khan, MCPS, DPH, MBA, PGD Statistics, DCPS-HCSM, DCPS-HPE, CCRP Department of Community Medicine,

4. Dr. Rashid Naseem Khan, MCPS, MD. Department of Medicine,

1-4: Liaquat College of Medicine \& Dentistry, Karachi, Pakistan. 